\title{
SIZING OF WIND POWERED AXIAL FLUX PERMANENT MAGNET ALTERNATOR USING ANALYTICAL APPROACH
}

\author{
A. 0. Otuoze ${ }^{1,}$, , 0. O.0gidi' ${ }^{2}$, 0. 0. Mohammed $^{3}$, A. A. Jimoh ${ }^{4}$ and B. S. Olaiya ${ }^{5}$ \\ 1,3,4,5DePT. OF ElECTRICAL AND EleCtronics ENGINEERING, UNIVERSITY OF ILORIN, ILORIN, KWARA STATE, NIGERIA \\ 2DEPARTMENT OF ELECTRICAL ENGINEERING, UNIVERSITY OF CAPE TOWN, SOUTH AFRICA \\ E-mail addresses: ${ }^{1}$ otuoze.ao@unilorin.edu.ng, ${ }^{2}$ dapoogidi@yahoo.com, ${ }^{3}$ oomohammed@unilorin.edu.ng, \\ 4jimohabdulramonaroyehun@gmail.com, 5 basiraholaiya@gmail.com
}

\begin{abstract}
The demand for a more sustainable energy supply worldwide is constantly growing hence, leading to the exploration of various renewable energy sources in energy generation systems especially in the demand for power in homes, industrial sectors and other utilities. Hydro power, wave power, solar energy, biomass and wind power are only a few that are being harnessed in various capacities. With new advances in wind energy technologies and energy conversion systems, a perfect fit is found in the utilization of wind in developing direct drive energy conversion systems. In this work, a wind-powered, single-phase, permanent magnet alternator utilizing an axial flux distribution system is developed. Using analytical calculations, the design parameters of the alternator's main dimensions were obtained in a similar procedure for conventional electrical machines. To prove the feasibility of the concept, a prototype was built and tested. The alternator was built using Neodymium Iron Boron (NdFeB), a permanent magnet, with high concentration of flux around its periphery. The stator is slot-less and carries a concentrated air-cored type of winding. The procedures leading to either the selections and/or calculations for the machine parameters were carried out from first principle and fundamental assumptions in electrical machines design were made accordingly. Tests were conducted to determine its voltage output and were found optimal giving the abound limitations as stated.
\end{abstract}

Keywords: Wind-Power, Axial flux, Axial Flux Permanent Machines (AFPM), Axial Flux Permanent Magnet Alternator (AFPMA), Neodymium Iron Boron ( $\mathrm{NdFeB}$ )

\section{INTRODUCTION}

As the demand for a more sustainable energy supply is ever-growing, renewable energy is found to play a vital role in power industry in fulfilling the growing demand for power in homes, industrial sectors, offices and other utilities. Clean, Green, Cheap and efficient renewable energy sources are top priorities. Hydro power, wave power, solar energy, biomass and wind power are being harnessed in various capacities. Wind energy plays a central role in most countries' immediate and long term energy plans with total installed commercial capacity totaling $370 \mathrm{GW}$ in 2014 [1]. While in Nigeria, wind energy remains largely untapped despite a bright prospect of wind power as one of the lowest cost renewable energy resources [2].Using wind power to produce electricity is a perfect choice for direct drive since maintenance requirement will be significantly reduced [3], low cost applications in the development of renewable energy and has been found largely reliable with new advances in wind energy technology[4]. In harnessing wind energy for power generation, a high constraint is the relatively low wind speed available and so, has become necessary to devise a means of better utilization of the available wind energy. Many types of alternator concepts have been proposed and in use for the conversion of wind power into electricity with the aim of achieving a configuration suitable for the lowspeed operation of a direct drive wind energy conversion system (DDWECS). DDWECS is generally employed as concise designs with notable decrease in the system size, weight and noise can be achieved while increasing overall efficiency and reliability [5]. 
Various direct drive wind powered generators have been explored in [6-8]. In this quest, Permanentmagnet (PM) machines are chosen and increasingly becoming dominant with the cost competitiveness of high energy permanent magnets. Significant developments of permanent magnet materials have been achieved as well as improvements on their properties for various applications [9]. These machines offer many unique features. They are usually more efficient because of the fact that field excitation losses are eliminated resulting in significant rotor loss reduction, so PM machines with coreless stators are regarded as high efficiency machines for distributed power generation [10-12]. These have advantages of high efficiency and reliability, since there is no need of external excitation and conductor losses are absent from the rotor.

Basically, PM machines can be divided into radial-flux machines (RFM) and axial-flux machines (AFM), according to the flux direction in the air gap $[1,13]$. Transverse flux machines (TFM) exist, but do not seem to have gained a foothold in wind power generation [13] and hence, are rarely discussed. The availability of modern high energy density magnet materials, such as Neodymium Iron Boron ( $\mathrm{NdFeB}$ ), has made it possible to design special topologies such as toothless stators with air gap windings [7]. Because of the absence of core losses, a generator with this type of design can potentially operate at a higher efficiency than conventional machines [11]. The noise and vibration they produce are less than those of conventional machines [12].

Axial-flux machines have now been adopted as the solution for certain applications such as electric traction or elevation [14] due to its advantages. Varieties of Axial Flux Permanent Magnet (AFPM) Machines have been presented in $[1,13,15]$ with some notable advantages such as compact machine construction and short frame, hence, smaller in size than their radial flux counterparts [15]; high power density; high efficiency [16] since there is no rotor copper losses due to the permanent-magnet excitations; more robust structure than cylindrical type; can be designed to have a higher power-toweight ratio resulting in less core material and higher efficiency [7, 15-18], the compactness and disk-shaped profile make these type of machines particularly suitable for mechanical integration with wind turbines[11]. It has also got its drawbacks which include the existence of complicated machine topology with two air gaps[19] and high windage losses at high- speed applications which can be decreased to some extent by placing the machine in a vacuum seal, especially when combined with a flywheel[20]. A design of a high speed AFPM generator was presented in [21].

This paper presents a single stator, double rotor AFPM developed by analytical procedures aimed at achieving a simple construction for the main dimensions. From first principle, the main machine's dimensions are determined; reasonable estimates within theoretical fundamentals are made and applicable assumptions were also noted in selecting some parameters needed for a detailed design as applicable in electrical machines.

\section{THE MACHINE STRUCTURE}

AFM is comprised of at least one rotor disc carrying either a slot-less or slotted stator winding and utilizes PM. The stator may be magnetic or non-magnetic depending on the machine topology adopted[22]. In most designs, coreless stator configurations are considered since the associated eddy and hysteresis losses will be eliminated due to absence of ferromagnetic materials[16]. Usually, AFPM machines are formed by a rotor disc carrying magnets that produce an axial flux and a stator disc containing the phase windings[5], Fig.1[23] shows a typical example of an Axial Flux Permanent Magnet (AFPM) alternator. Magnets are positioned circumferentially around each rotor disc with the armature winding positioned circumferentially around each stator disc[15], and are lied side by side. Axial flux machines are different from the conventional radial machine types in that the direction of the flux runs parallel with the mechanical shaft of the machine. The current flowing through each stator coil interacts with the flux created by the magnets on the rotor, producing a force tangential to the rotor circumference[19] which consequently aid the driving of the rotor. For slotted stator, the interaction between rotor magnets and stator teeth can produce torque ripple in the machine [24]. A cross section of a typical AFPM Machine is shown in Fig. 2 [8] with $l_{g}$ indicating the length of air gap, $r_{0}$ and $r_{i}$, the outer and internal radius respectively.

Based on these concepts, a large number of AFPM topologies are explored including single-sided, double-sided or multistage designs[22]. AFPM machines can be classified in terms of its stator-rotor arrangements as Single-Rotor Single-Stator Structure or Double-Sided Structure $[8,18]$. 




Fig.1: Axial-Flux Permanent-Magnet Alternator

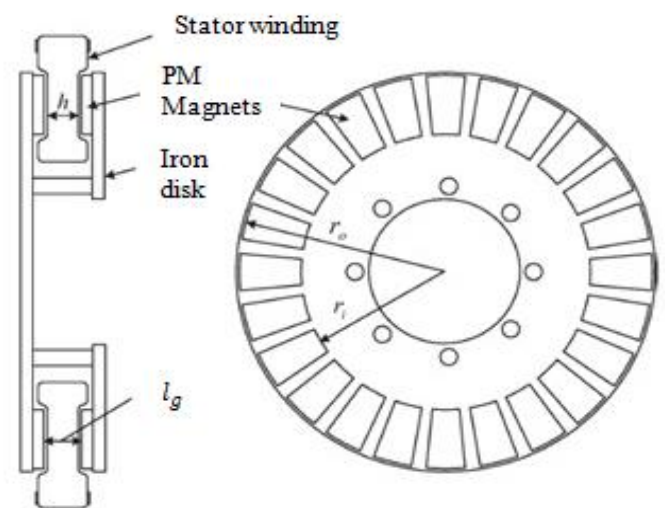

Fig. 2: A cross section of an Axial Flux Permanent Magnet Machine

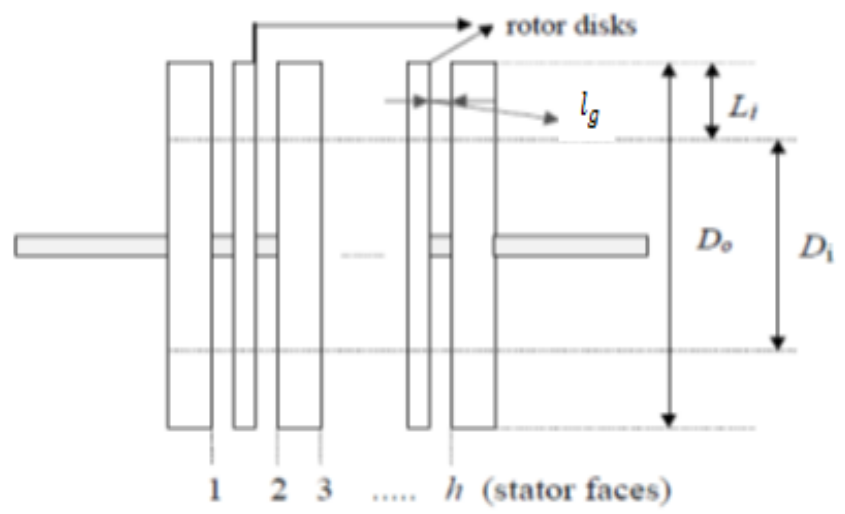

Fig.3: Simplified Representation of an AFPM Machine.

The Single-Rotor Single-Stator structure is the easiest and the cheapest but associated with relatively low torque production and large magnetic pull between the two parts and so, it is not very popular[19].

In the double-sided structure, the high attractive forces between the stator and the rotor is counterbalanced by the use of a second stator or rotor mounted as a mirror image of the other with either the rotor or the stator positioned internally. The Double sided structures are the most promising and widely used types. A multiple configuration consisting of multiple stator-multiple rotor cascades have also been developed. This helps to eliminate the mechanical stress that may exist between the stator and the rotor [3], therefore, boosting the torque production and increases its efficiency but with the drawbacks of the associated complicated machine topology with as many air-gaps as the number of faces. It could also be classified in terms of its arrangement of permanent magnets on the rotor. The magnets could be of the surface mounted types or interior PM type machines having its magnets embedded in the iron, the classification could be based on the arrangement of the armature slots as toroidally wound slot-less stator or slotted stator[5, 8, 23].Low speed AFPMs are designed for use with inverter systems. In this design, single-stator double-rotor is developed. General limitations abound which determines finally, the topology one settles for with optimum trade-off.

\section{MATHEMATICAL FORMULATION}

General purpose voltage equations for axial flux machines have been provided in[19].The alternator is designed utilizing axial flux distribution system with the configuration known as "Double-Rotor SingleStator" topology. Axial flux machines can well be modeled using FEA [14], however, the analytical solution presented fares well in understanding the basic principle of the design approach.

Consider an axial flux machine whose simplified representation is as given in Fig. 3 [19]. 
In Fig. 3, $L_{i}$ is the effective length of the stator core in radial direction, $D_{o}$ is the outer diameter with radius $r_{0}, D_{i}$ is the internal diameter with radius $r_{i} l_{g}$ is the air gap length, $D_{a v}$ is the average diameter of the stator given in equation (1). That is:

$$
D_{a v}=\frac{D_{o}+D_{i}}{2}
$$

\subsection{Specific Electric Loading}

This is the number of ampere-conductors per meter of the armature (stator) periphery, and it can be expressed as[19] the specific electric loading, $\mathrm{k}_{1}$ given by:

$$
\begin{gathered}
k_{1}=\frac{\text { Total max. ampere }- \text { conductors }}{\text { armature circumference }} \\
=\frac{2 \sqrt{2} I_{p h} N_{p h}}{\pi D_{a v}} A / m
\end{gathered}
$$

In (2), $I_{p h}$ is the stator phase current and $N_{p h}$ the number of turns per phase. Therefore,

$$
I_{p h}=\frac{k_{1} D_{a v} \pi}{2 \sqrt{2} N_{p h}}
$$

The amplitude of the surface current density $k$ ranges from $10,000 \mathrm{~A} / \mathrm{m}$ for small machines to $40,000 \mathrm{~A} / \mathrm{m}$ for medium power machines [19]. In this design, $14000 \mathrm{~A} / \mathrm{m}$ is selected since the developed prototype is a very small machine and hence should be lightly loaded. This selection also has direct impact on the size of conductor that will be used for the winding.

\subsection{Specific Magnetic Loading}

This refers to the average flux density over the air-gap of a machine. Mathematically, it is given by [25] as:

$$
\begin{array}{r}
B_{g}=\frac{\text { total flux around the air }-g a p}{\text { area of flux path at the air }- \text { gap }} \\
=\frac{P \emptyset}{\pi D_{a v} L_{i}}[\text { Tesla }]
\end{array}
$$

In (4), $P$ and $\varnothing$ being the number of poles and the value of flux per pole.

In some designs, where PM are not used, the value of $B_{g}$ can be calculated using equation (4) but in this case it is the value of the field intensity of the PM. Specific loadings. Therefore, its value depends on the choice of PM employed.

\subsection{Choice of Permanent Magnet, Number of Poles and the Speed}

The performance and the cost of the machine largely depend on the dimensions of the PM used. The choice of the PM's width to pole pitch ratio $\left({ }^{w_{p}} / \tau_{p}\right)$ is a very vital criterion. For higher values of this ratio; 1 for instance, flux linkage is assumed maximum, but also flux leakage due to adjacent permanent magnets is high. By decreasing the permanent magnet width, linkage and leakage fluxes are both decreased though not proportionally.

In this configuration, permanent magnet known as Neodymium-Iron-Boron (NdFeB) is utilized. This selection is due to its high flux density and its high corrosive resistance. Depending on the number of poles and the geometry of the surface, emphasis is laid on ensuring sufficient value of flux that will be linked with the coils during operation. Although, the design of the prototype given in this work was made under geometrical constraints imposed by the available ferromagnetic material, due to its wind application purpose, i.e. low speed consideration of the direct driven alternator, a large number of poles should be chosen. The stochastic nature of the direct wind drive is a noted factor; the speed was to be assumed at a safe range of 200 to $250 \mathrm{rpm}$ with the mechanical design to take care of the required inertia and driving torque, hence requiring between 24 to 30 poles. But for this work, only 8 poles of the $\mathrm{NdFeB}$ were available.

\subsection{EMF Equations}

For an axial flux permanent magnet generator, the waveform of the air-gap flux are sinusoidal by ensuring alternate arrangements of the magnetic poles on the rotor, consequently giving a sinusoidal emf waveforms whose rms phase equation can be expressed as in [9]:

$$
E_{p h}=\frac{\sqrt{2}}{2} B_{g} w_{m} k_{w} N_{p h} D_{a v} L_{i} \quad[\text { volts }]
$$

In (5), $B_{g}$ is the air-gap flux density. The fundamental component of the air-gap flux density due to the permanent magnets is normally used; $w_{m}$ is the mechanical speed of the rotor in r.p. sand $k_{w}$, the winding factor.

\subsection{Power Output Equations and the Main Dimensions}

The main dimensions of machines is comprised basically, the axial length, $L_{i}$ and the stator bore, $D_{a v}$. In some books, the length of air gap, $l_{g}$ is thought to be part of the machines' main dimension.

The inside apparent power of the machine with an mphase stator-system can be calculated, from first principle, using equation (6).

$$
S=m h E_{p h} I_{p h} \quad(V A)
$$


with $h$ being the number of stator faces and $m$ the number of winding phases. In this design, the number of stator faces, $h$, equals 2 .

Substituting equations (3) and (5) in (6), the apparent power, $S$ can then be expressed as

$$
S=\pi \frac{h}{4} B_{g} w_{m} k_{w} k_{1} D^{2}{ }_{a v} L_{i}
$$

Equation (7) can be re-written as

$$
S=\left(\pi \frac{h}{4} B_{g} k_{w} k_{1}\right) D^{2}{ }_{a v} L_{i} w_{m}
$$

and

$$
S=C_{o} D^{2}{ }_{a v} L_{i} w_{m}
$$

In (9), $C_{o}$ is the output coefficient of the AFPM alternator. From Eqn. (7), the main dimensions can be determined using the ratio of length to pole pitch, $L_{i} / \tau_{p}=k$, as a separating parameter for $D_{a v}$ and $L_{i}$. This ratio is taken as 1 for the design of this machine because lower values may lead to lower average diameter of the stator since larger diameter is required to accommodate the high number of poles. The winding factor, $k_{w}$ is also taken as 1 for single phase winding, as employed in this work.

Therefore,

$$
L_{i}=\tau_{p}=\pi D_{a v} / p \quad[\mathrm{~m}]
$$

Substituting equation (10) in (9), the average diameter of the stator is modeled as:

$$
D_{a v}=\sqrt[3]{\frac{p S}{C_{o} \pi w_{m}}}=\sqrt[3]{\frac{4 p S}{\pi^{2} h B_{g} w_{m} k_{1}}}[\mathrm{~m}]
$$

Other separating or limiting factors such as Peripheral speed limitation and moment of inertia can be considered in arriving at the required values of $L_{i}$ and $D_{a v}$.

The length of air-gap, $l_{g}$ is often expressed as

$$
l_{g}=0.2+\sqrt{D_{a v} L_{i}} \quad[\mathrm{~mm}]
$$

With the values of $D_{a v}$ and $L_{i}$ used in metres. Using the designed AFPM parameters, the expected emf equation given in (5) in term of speed, $w_{m}$, is

$$
E_{p h}=1.36 \times 10^{-3} w_{m} \quad[\text { volts }]
$$

And the apparent power, $S$, is

$$
S=1.126 \times 10^{-5} w_{m} k V A
$$

\section{SIZING OF THE CONDUCTORS AND WINDING ARRANGEMENT}

Using eqn. (3), the nominal stator phase current is evaluated choosing a suitable value for electrical loading, $k_{1}, 14000 \mathrm{~A} / \mathrm{m}$ as stated earlier. The appropriate cable size is then determined with a suitable selection of current density, $J$ using equation 4. The current density, $J$ ranges from 3 to $5 \mathrm{~A} / \mathrm{mm}^{2}$ for normal electrical loadings of machines[25].

$$
J=\frac{I_{p h}}{a}
$$

Where $a$ is the area of the conductor in $\mathrm{mm}^{2}$. The developed winding is as shown in Fig. 5

\section{CONSTRUCTION, TESTING AND RESULTS}

Using the developed equations and choosing suitable values as applicable, a prototype was developed. It was test-driven by a dc motor (rather than direct driven, for the purpose of testing) with variable speed regulations.

The diagrammatic arrangement of the single phase, air-cored and slot-less stator winding for the constructed axial flux, surface mounted, slot-less permanent magnet alternator is as shown in Fig.4. It is important to note that there are as many coils as the number of poles, for this machine. Here the coils 1 to 8 are linked together by end to end connections forming a series end winding. Fig. 6 presents the arrangement of the PM on the rotor.

The no load measured characteristics of the developed machine and its general characteristics are as presented in Table 1. Fig.7 and 8 show the permanent magnet mounted on the rotor and the test set-up for the developed AFPMA respectively. The measured results from the tests compared fairly with results from analytical calculations.

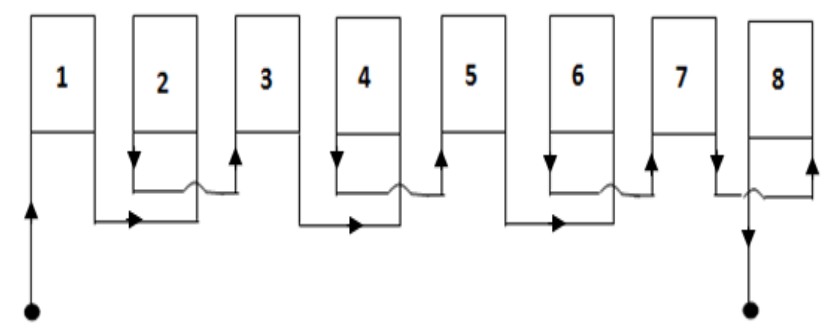

Fig.4: Single-phase Winding Arrangement on the slotless stator for the AFPM

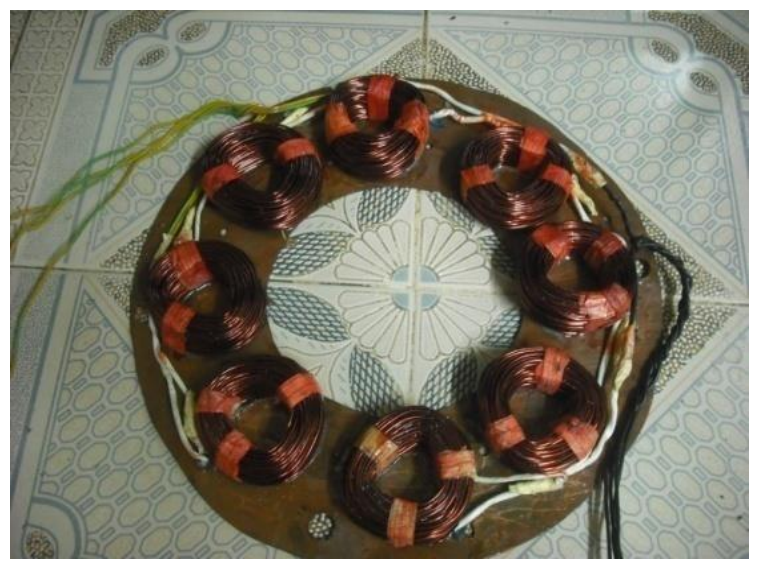

Fig.5: The developed Concentrated Air-Cored Stator Winding 


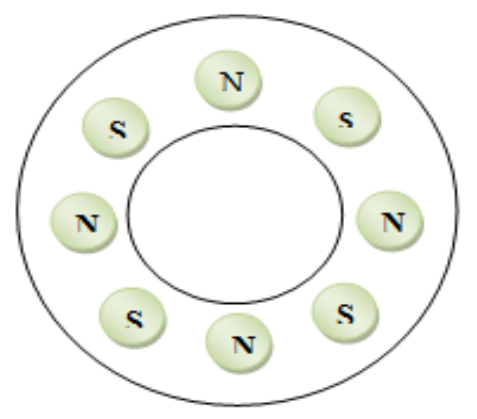

Fig. 6: Arrangement of PMs on the rotor

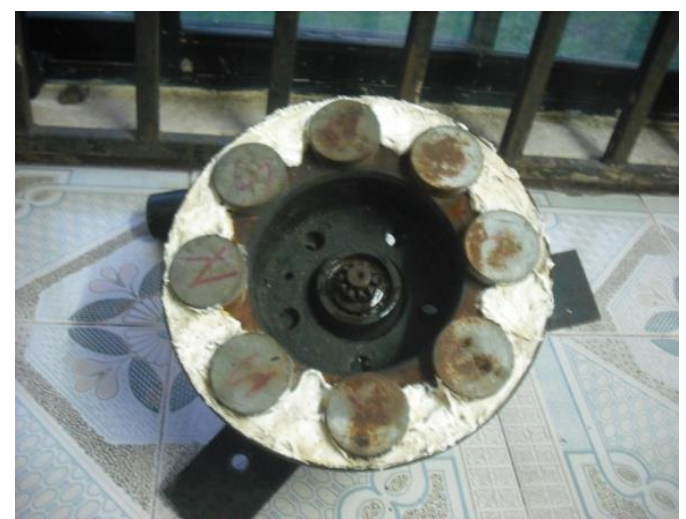

Fig. 7: Permanent magnets as mounted on the rotor plate

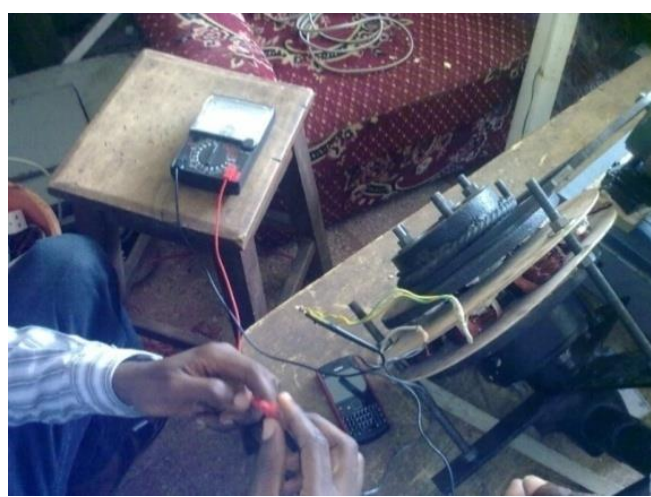

Fig. 8: Test Set-Up for the developed AFPMA

Table 1: The Machine Data

Parameters
Inner Diameter, $D_{i}$
Outer Diameter, $D_{o}$
No. of Poles, $p$
No. of faces, $h$
Length of stator in radial direction, $L_{i}$
Diameter of the permanent magnet
Length of air gap per face
No. of turns/coils
Diameter of the conductor
Assumed Specific Electric Loading, $k_{1}$
Air gap flux density, $B_{g}$
Rated speed
Calculated no-load phase voltage (at rated
Speed)
Measured no-load phase voltage (at rated
Speed)
Rated Power (Calculated)

$32 \mathrm{~mm}$ $15 \mathrm{~mm}$ 8 2

$8.5 \mathrm{~mm}$

$50 \mathrm{~mm}$ 8 $0.5 T$

$0.34 \mathrm{~V}$

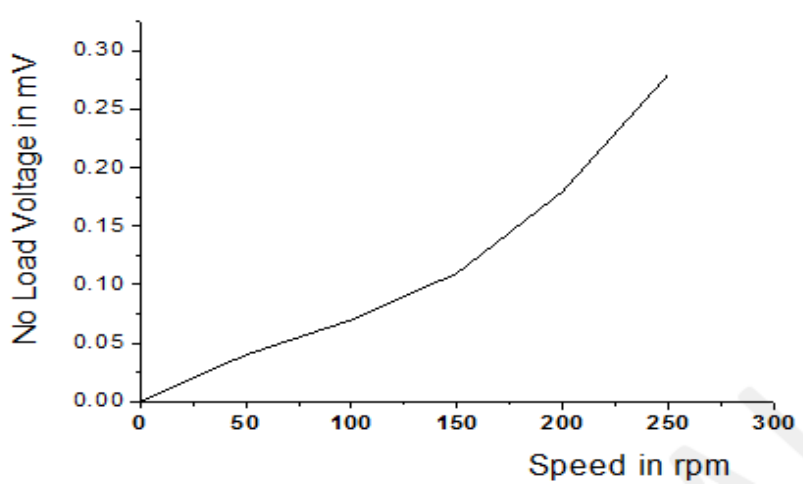

Fig. 9: Measured no load voltage of the developed machine

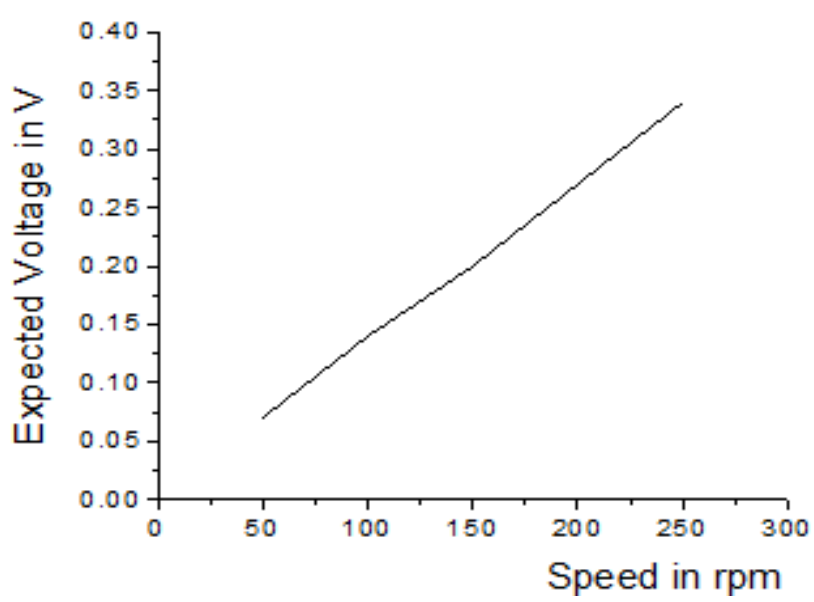

Fig. 10: Expected values of the no load voltage

\section{CONCLUSION AND RECOMMENDATIONS}

A test axial flux alternator has been developed in this paper, though measured values deviate from the predicted analytical results (Fig. 9 and 10) largely, with the validation of additional studies and application of proper optimization technique, a bigger and more refined prototype can be simulated and built for extensive field testing and applications, with the great promise it holds for low-speed wind generator applications

To scale up the output power of the alternator, the design can be readily improved such as the number of poles in one unit increased and/or incorporating more $0.2 \mathrm{~mm}$ number of unit modules stacked in the axial direction

$1.29 \mathrm{~mm}$ $14000 \mathrm{~A} / \mathrm{m}$ plate carrying the magnets should also be well coated

$250 \mathrm{rpm}$

\section{REFERENCES}

$0.28 \mathrm{mV}$

[1] 0. O. Ogidi, P. S. Barendse, and M. A. Khan, "Fault diagnosis and condition monitoring of axial-flux $0.00282 \mathrm{VA}$ permanent magnet wind generators," Electric Power Systems Research, vol. 136, pp. 1-7, 2016. 
[2] O. I. Okoro, E. Chikuni and P. Govender, "Prospect of Wind Energy in Nigeria", pp. [Accessed on Dec. 23rd 2015 via https://www.researchgate.net/ publication/228827644 Prospects of wind energy in Nigeria

[3] S. Djebarri, J. F. Charpentier, F. Scuiller, and M. Benbouzid, "Design and Performance Analysis of Double Stator Axial Flux PM Generator for Rim Driven Marine Current Turbines," IEEE Journal of Oceanic Engineering, vol. 41, pp. 50-66, 2016.

[4] S. Lindenberg, 20\% Wind Energy By 2030: Increasing Wind Energy's Contribution to US Electricity Supply: Diane Publishing, 2009.

[5] G. F. Price, T. D. Batzel, M. Comanescu, and B. A. Muller, "Design and testing of a permanent magnet axial flux wind power generator," in Proceedings of the 2008 IAJC-IJME International Conference, 2008.

[6] D. Bang, H. Polinder, G. Shrestha, and J. A. Ferreira, "Review of generator systems for direct-drive wind turbines," in European Wind Energy Conference \& Exhibition, Belgium, , pp. 1-11. 2008.

[7] Y. Chen, P. Pillay, and A. Khan, "PM wind generator topologies," IEEE Transactions on Industry Applications, vol. 41, pp. 1619-1626, 2005.

[8] R. Neji, M. Chaieb, and S. Tounsi, "Design and Optimisation of Axial Permanent Magnet Machine for Electric Vehicle," Journal of Electrical Systems, vol. 5, (1) 2009.

[9] E. Belicova and V. Hrabovcova, "Analysis of an axial flux permanent magnet machine (AFPM) based on coupling of two separated simulation models (electrical and thermal ones)," Journal Of Electrical Engineering-Bratislava-, vol. 58, p. 3, 2007.

[10] M. Aydin, S. Huang, and T. Lipo, "Axial flux permanent magnet disc machines: a review," Wisconsin Electric Machines \& Power Electronics Consortium, University of Wisconsin-Madison, Madison, WI, pp. 53706-1691, 2004.

[11] S. Hosseini, M. Agha-Mirsalim, and M. Mirzaei, "Design, prototyping and analysis of a low-cost disk permanent magnet generator with rectangular flatshaped magnets," Iranian Journal of Science and Technology, vol. 32, p. 191, 2008.

[12] A. Mahmoudi, N. Rahim, and W. Hew, "Axial-flux permanent-magnet machine modeling, design, simulation, and analysis," Scientific Research and Essays, vol. 6, pp. 2525-2549, 2011.

[13] B. Zhang, T. Epskamp, M. Doppelbauer, and M. Gregor, "A comparison of the transverse, axial and radial flux PM synchronous motors for electric vehicle," in Electric Vehicle Conference (IEVC), 2014 IEEE International, pp. 1-6. 2014.

[14] A. Egea, G. Almandoz, J. Poza, G. Ugalde, and A. J. Escalada, "Axial-flux-machine modeling with the combination of FEM-2-D and analytical tools," IEEE Transactions on Industry Applications, vol. 48, pp. 1318-1326, 2012.

[15] J. Bumby and R. Martin, "Axial Flux, Permanent Magnet, Generators for Engine Integration," in The 12th International Stirling Engine Conference. Durham, pp. 1-5. 2005.

[16] W. Geng, Z. Zhang, and K. Jiang, "A new control strategy of ironless stator axial-flux PM motor fed by inverter with output LC filter," in Industrial Electronics Society, IECON 2015-41st Annual Conference of the IEEE, pp. 2264-2269. 2015.

[17] M. A. Kabir, A. Ahmed, and I. Husain, "Axial flux segmental rotor flux-switching synchronous motor," in 2015 IEEE Energy Conversion Congress and Exposition (ECCE), pp. 2148-2152. 2015.

[18] H. Vansompel, P. Sergeant, L. Dupré, and A. Van den Bossche, "Axial-flux PM machines with variable air gap," IEEE Transactions on Industrial Electronics, vol. 61, pp. 730-737, 2014.

[19] F. F. Sahin, "Design and development of a highspeed axial-flux permanent-magnet machine," Technische Universiteit Eindhoven, 2001.

[20] A. El shahat, A. Keyhani, and H. El Shewy, "Spacecraft Flywheel High Speed PM Synchronous Motor Design (Classical \& Genetic)," Journal of Theoretical and Applied Information Technology, pp. 83-100, 2005.

[21] H. Lesani, H. Monsef, and A. Darabi, "Design considerations of high speed axial flux permanent magnet generator with coreless stator," in 2007 International Power Engineering Conference (IPEC 2007), pp. 1097-1102. 2007.

[22] M. Mardaneh, M. Mirsalim, and M. AliAhmadi, "A Modified Analytical Approach in Modelling and Design of Axial-Flux Permanent Magnet Machines," Amirkabir (Electrical Engineering), vol. 17, 2006.

[23] H. Vansompel, "Maximizing the energy output of an axial flux permanent magnet generator for a small wind energy application," in 11th UGent-FirW PhD Symposium, 2010, pp. [Accessed on Dec. 25, 2015] via http://symposium.elis.ugent.be/sites/ symposium.elis.ugent.be/files/phdsymposium/pap er644poster_6.pdf

[24] L. Chong, R. Dutta, and M. Rahman, "Application of concentrated windings in the interior permanent magnet machine," Australian Journal of Electrical and Electronics Engineering, vol. 5, pp. 229-236, 2008.

[25] A. Sawhney and A. Chakrabarti, "Electrical machine design," Dhanpat Rai \& Sons, New Delhi, India, 1984. 